\title{
Intracerebral Implantation of Hydrogel-Coupled Adhesion Peptides: Tissue Reaction
}

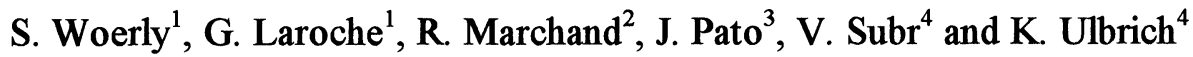 \\ ${ }^{1}$ Québec Biomaterials Insitute, Hôpital Saint-François d'Assise, Québec, Canada \\ ${ }^{2}$ Centre de Recherche en Neurobiologie, Hôpital de l'Enfant-Jésus, Québec, Canada \\ ${ }^{3}$ Central Research Institute for Chemistry, Budapest, Hungary \\ and ${ }^{4}$ Institute of Macromolecular Chemistry, Czech Academy of Sciences, Prague, Czech Republic
}

\section{SUMMARY}

Arg-Gly-Asp peptides (RGD) were synthesized and chemically coupled to the bulk of $\mathrm{N}-(2-$ hydroxypropyl) methacrylamide-based polymer hydrogels. Fourier Transform Infrared Spectroscopy (FTIR) and amino acid analysis confirmed the peptide coupling to the polymer. Activated and control (unmodified) polymer matrices were stereotaxically implanted in the striata of rat brains, and two months later the brains were processed for immunohistochemistry using antibodies for glial acidic fibrillary protein (GFAP), laminin and neurofilaments. RGD-containing polymer matrices promoted stronger adhesion to the host tissue than the unmodified polymer matrices. In addition, the RGD-grafted polymer implants promoted and supported the growth and spread of GFAP-positive glial tissue onto and into the hydrogels. Neurofilament-positive fibers were also seen running along the surface of the polymer and, in some instances, penetrating the matrix. These findings are discussed in the context of using bioactive polymers as a new approach for promoting tissue repair and axonal regeneration of damaged structures of the central nervous system.

\footnotetext{
Reprint address:

Dr. S. Woerly

Institut des Biomatériaux

Hôpital Saint-François d'Assise

10 rue de l'Espinay

Québec G1L 3L5, Canada
}

\section{KEY WORDS}

hydrogels, peptides, intracerebral implantation, regeneration, plasticity

\section{INTRODUCTION}

Fetal neural grafts, when transplanted into damaged regions of the central nervous system (CNS), can compensate for tissue damage and promote reorganization of the neural circuit. Alternatively, a synthetic polymer scaffold may provide an extracellular matrix (ECM) that assists the course of tissue healing so that new tissue can be constituted with the CNS's own tissue constituents, enabling axonal regeneration to occur $/ 27 /$. The combination of these two approaches, namely entrapment of fetal grafts within a polymer scaffold, is attractive because it may allow us to produce cell-based polymer hybrid devices that associate properties of biocompatible polymers with those of physiologically active cells for replacement of tissue mass and function $/ 29 /$. However, one critical issue in the design of polymer matrices for brain tissue implantation is the properties of the polymer surface that interfaces with the host tissue, as these determine the type of tissue response and the fate of the polymer matrix in the host. The polymer surface can be tailored with biomolecular cues that may optimize the function of the implanted polymer matrices by promoting a specific response from host cells, such as selective binding and axonal regeneration. In this respect, short peptides containing the Arg-Gly-Asp (RGD) sequences found in many proteins of ECM and which are related to cell-binding and cell-ECM recognition processes have incited a great deal of interest because they provide a unique model for the 
study of cell receptor-ligand interactions in relation to biological activities. Such sequences can be synthesized and immobilized on a polymer surface, thereby reproducing the chemical environment of ECM. Thus, polymer substrates grafted with bioactive peptides have been shown to support attachment and spreading of a variety of cells /4/ and neurite outgrowth was shown to occur on laminin oligopeptide immobilized surfaces $/ 3 /$.

In the present study synthetic hydrogels were modified by covalently coupling the tripeptide ArgGly-Asp to the polymer network of synthetic hydrogels. RGD peptide sequences are specifically recognized by integrin cell surface receptors $/ 20,30 /$ and constitute a recognition system which is involved in cell adhesion, migration and growth during tissue remodelling and regeneration /20/. RGD-adhesion receptor systems have been shown to be expressed by neural and glial cells $/ 3,13,16,26$, and it was expected that RGD-coupled polymer matrices would be able to induce a different tissue reaction to that which follows injury by promoting tissue adhesion and cell growth, and thus form a solid integration of the polymer matrix to the host tissue. RGD peptides were chemically attached to the bulk of N-(2-hydroxypropyl) methacrylamide-based hydrogels using glycylglycine spacers. Such bioactive polymer hydrogels were implanted into the striata of adult rat brains and the tissue reaction was examined two months later using standard immunocytochemical methods. The potential of bioactive polymer matrices as brain tissue implants is discussed in the context of the emerging field of neural tissue engineering as a new method of repairing structural brain damage and promoting axonal regeneration.

\section{MATERIAL AND METHODS}

\section{RGD peptide synthesis}

The protected amino acids, Asp dibenzylester, Boc-Gly, and carbobenzyloxy nitro-arginine were prepared according to standard methods. The peptide coupling (BocGlyAspOBzl, $\mathrm{ZNO}_{2}$ ArgGlyAsp OBzl) was carried out using the standard solution phase method with isobutyl chloroformate $\left(\mathrm{ZNO}_{2}\right.$ ArgGlyAspOBzl). Removing the $Z$ and benzyl protecting groups of fully protected peptides was achieved by catalytic hydrogenation and the Boc group was removed by $\mathrm{HCl}$ in ethylacetate. The free peptide was purified on a Sephadex G-25 column. The RGD fraction was collected and freeze-dried.

\section{Synthesis of HPMA copolymers}

$\mathrm{N}$-(2-hydroxypropyl) methacrylamide [1] and methacryloylglycylglycine p-nitrophenyl ester (MaGlyGlyONp) [2] were prepared according to previously described procedures $/ 16,22 /$. Other monomers - 2-hydroxyethyl methacrylate [3] and triethyleneglycol dimethacrylate [4] - from Rohm and Haase (Germany), were purified by vacuum distillation. The synthesis of the coupling reactions and the synthesis of the activated gels are shown in Fig. 1.

\section{Preparation of methacryloylglycylglycylargynylglycyl- aspartic acid [5]}

The synthesis of [5] involved the aminolysis of [2] with the aliphatic $\mathrm{NH}_{2}$ group of Arg /18/. MaGlyGlyONp $\left(0.04 \mathrm{~g}, 1.2 \times 10^{-4} \mathrm{~mol}\right)$ was dissolved in dry DMSO $(0.5 \mathrm{ml})$ and the solution was purged of oxygen with nitrogen. Under continuous stirring, RGD (0.05 g, $\left.1.4 \times 10^{-4} \mathrm{~mol}\right)$ was added to [2]. Afterwards $1 \mathrm{~h}$ triethylamine $\left(0.023 \mathrm{~g}, 2.3 \times 10^{-4} \mathrm{~mol}\right)$ was added to the reaction mixture in equimolar ratio to $\mathrm{ONp}$ ester. The reaction was carried out overnight at room temperature. After the reaction octylpyrocatechin as a polymerization inhibitor was added and DMSO was removed using a rotatory vacuum evaporator at $40^{\circ} \mathrm{C}$. The oil residue was triturated with dry diethylether $(6$ times $5 \mathrm{ml})$. The white precipitate was filtered, washed with diethylether and dried under vacuum. The crude product was used for polymerization without further purification.

\section{Synthesis of hydrogel containing RGD}

Hydrogels were synthesized by radical crosslinking polymerization in DMSO at $60^{\circ} \mathrm{C}$ for $24 \mathrm{~h}$ using AIBN as an initiator $(0.6 \% \mathrm{wt} / \mathrm{wt})$. The polymerization mixture was purged with nitrogen for 3 min. The reaction was carried out between two Teflon plates connected by silicone rubber sealing and thermostated. The concentration of monomers [1], [3], [4] was 14.8: 22.2: $1.4 \mathrm{wt} \%$ and the 


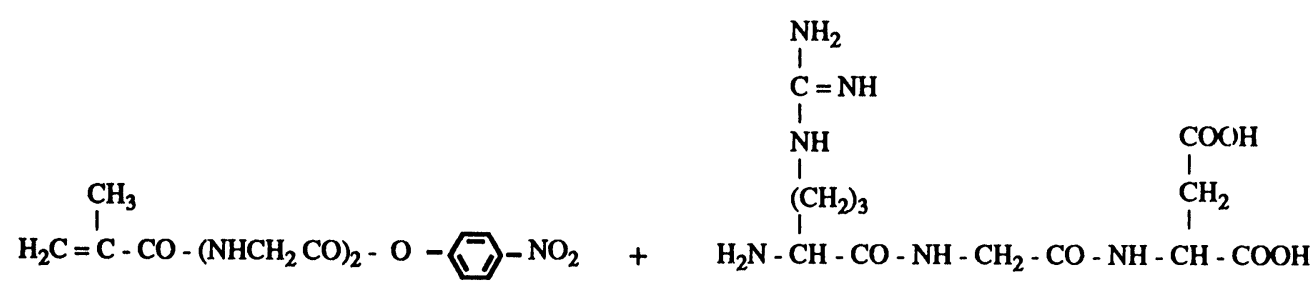

[2]

[RGD]

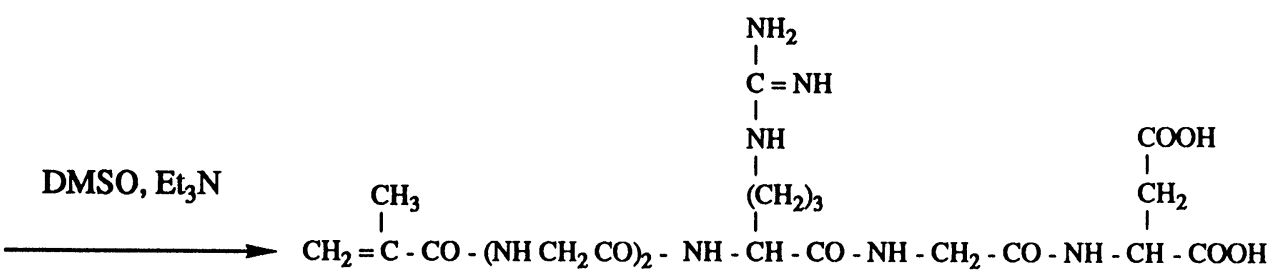

[5]

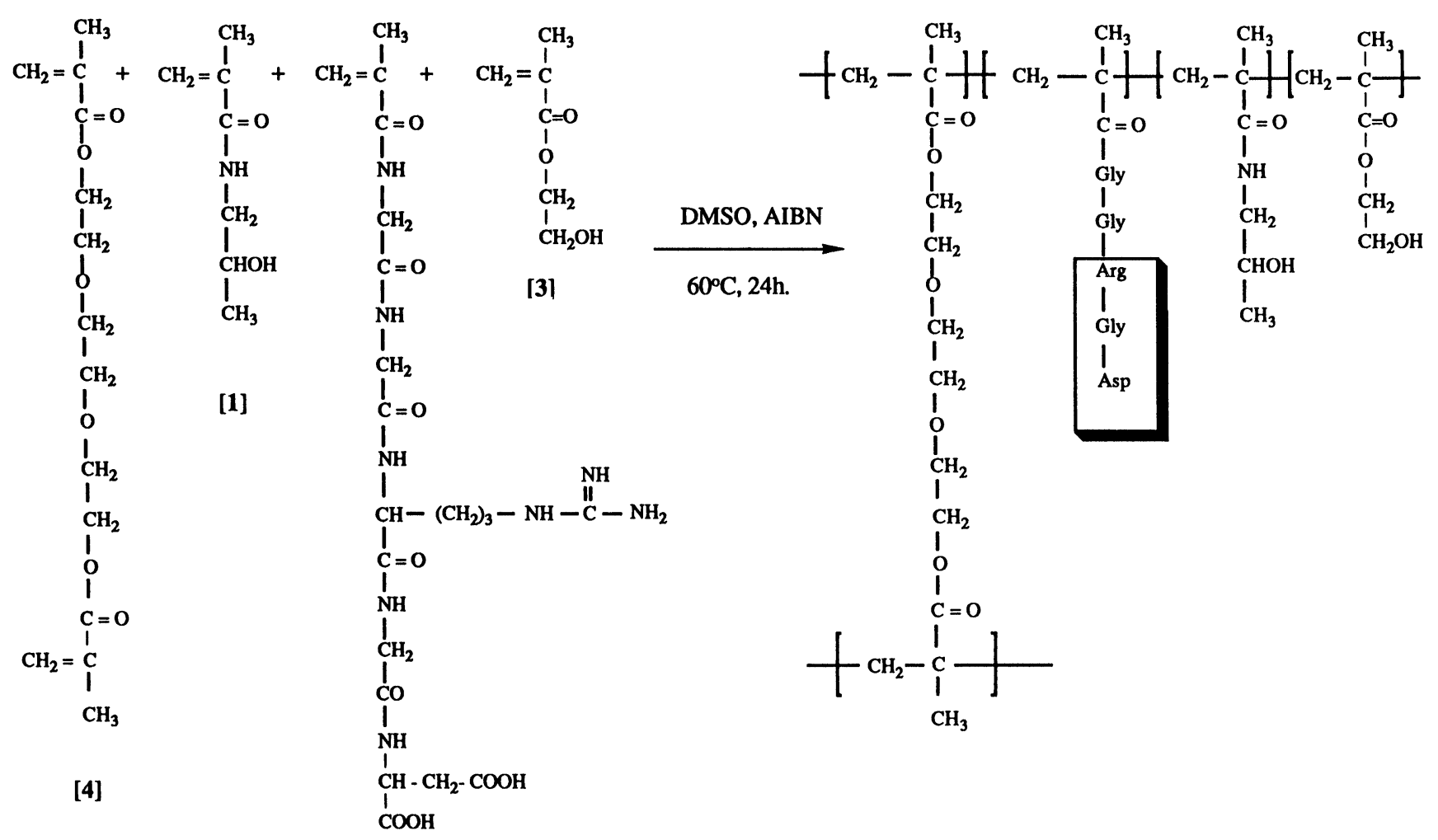

[5]

Fig. 1: Reaction schemes for the synthesis of RGD-grafted hydrogels. 
concentration of [5] was $1.7 \mathrm{wt} \%$ (gel 1) and 1.18 wt\% (gel 2). After polymerization the gels were washed in ethanol and swollen in ethanol/water (1:1 $\mathrm{v} / \mathrm{v}$ ). The thickness of the gels was $1.5 \mathrm{~mm}$.

\section{Amino acid analysis}

Amino acid analysis was carried out on an Amino Acid Analyser (LDC Analytical, USA) with a reverse phase column C18 $(250 \times 4 \mathrm{~mm})$ using ophthaldialdehyde (OPA) precolumn derivatization. A fluorescence detector Fluoro-Monitor 4100 (LDC Analytical) was used for detection (Ex 330 $\mathrm{nm}, \mathrm{Em} 450 \mathrm{~nm}$ ). The mobile phase consisted of a mixture of buffer $\mathrm{A}(0.05 \mathrm{M}$ sodium acetate $\mathrm{pH} 6.5)$ and buffer $B$ (methanol: $0.1 \mathrm{M}$ sodium acetate; $1: 1$ ) with a gradient of concentration increasing from $0 \%$ B to $100 \%$ B within $45 \mathrm{~min}$ at a flow rate of 0.5 $\mathrm{ml} / \mathrm{min}$.

The hydrogel samples (free of low molecular weight impurities) were hydrolyzed with $200 \mu 16 \mathrm{~N}$ $\mathrm{HCl}$ at $115^{\circ} \mathrm{C}$ for $16 \mathrm{~h}$. The hydrolyzate was dried in vacuo over $\mathrm{NaOH}$, dissolved in distilled water and, after OPA derivatization, $20 \mu \mathrm{l}$ was used for injection.

\section{Attenuated total reflection-Fourier transform infrared (ATR-FTIR)}

Infrared (i.r.) spectra were recorded with a Nicolet Magna-550 Fourier transform infrared spectrometer with a DTGS detector and a germanium coated $\mathrm{KBr}$ beamsplitter. Two hundred and fifty scans were acquired with an optical retardation of $0.25 \mathrm{~cm}$, triangularly apodized and Fourier transformed to yield a $4 \mathrm{~cm}^{-1}$ resolution. The attenuated total reflectance (ATR) mode was used for recording the infrared spectra of the hydrogel samples with a Split Pea attachment (Harrick Scientific Corporation) equipped with a $\mathrm{Si}$ hemispherical, 3 $\mathrm{mm}$ diameter internal reflection element (IRE). The IRE was beveled on the edge of its flat surface to provide a sampling area slightly larger than the 150$200 \mu \mathrm{m}$ diameter hot spot on the crystal.

\section{Implantation and tissue processing}

Twelve young Sprague-Dawley rats (250 g) were used as recipients. Rats were anesthesized by an intramuscular injection $(1 \mathrm{mg} / \mathrm{kg})$ of a solution containing ketamine hydrocholoride $(87 \mathrm{mg} / \mathrm{ml})$ and xylazine $(13 \mathrm{mg} / \mathrm{ml})$, and placed in a stereotaxic head frame. Under a surgical microscope, a small craniotomy was made over the left parietal cortex. Hydrogels were cut into $2 \times 1.5 \mathrm{~mm}$ size pieces which were implanted into the striatum of the rat brain using the following coordinates: bregma -0.8 ; lateral 3.6; vertical 5.2 (Paxinos G. and Watson C.). First, a channel was created through the cortex up to the stereotaxic point using a capillary glass tube with an opening of $1.5 \mathrm{~mm}$. The polymer implant was then slowly inserted into the preformed channel using the glass tube. Of the host rats, two received unmodified HPMA polymer and two were sham operated.

Two months after implantation, the animals were deeply anesthetized and perfused with PBS containing heparin, followed by $4 \%$ paraformaldehyde in PBS. Brains were post-fixed overnight, the implant area blocked out and transferred in 30\% buffered sucrose. Coronal brain sections $(40 \mu \mathrm{m})$ were cut with a cryostat and processed using standard procedures for indirect immunohistochemistry. The following antibodies were used: glial fibrillary acidic protein (GFAP, Dako), 200-kDa neurofilaments (NF, Sigma) and laminin (LN, Sigma). Sections were preincubated for 30 minutes with $10 \%$ normal goat serum in DPBS (Dulbecco) and then with the above antibodies diluted in DPBS containing $0.1 \%$ bovine serum albumin (BSA, Sigma) and $0.2 \%$ Triton at the following concentrations: GFAP (1:200), LN (1:200) and NF (1:64). GFAP and LN were incubated with the tissue overnight at room temperature and under agitation, while NF was incubated for $48 \mathrm{~h}$ at $4^{\circ} \mathrm{C}$. After washing in DPBS ( $3 \times 10$ minutes), sections were incubated for 2 hours with a sheep anti-mouse FITC (Sigma) or with RITC (Dako), at a dilution of $1: 100$ in $0.1 \% \mathrm{BSA} / \mathrm{DPBS} / 0.2 \%$ Triton. Sections were then washed in DPBS for $3 \times 10$ minutes, mounted onto slides, and coverslipped in a mixture of glycerol-water. They were then examined on a Nikon fluorescent microscope. Additional sections were stained with hematoxylin-eosin (H\&E). To visualize the gel implants, sections were observed on an Olympus inverted microscope equipped with a Hoffman modulation contrast system.

JOURNAL OF NEURAL TRANSPLANTATION \& PLASTICITY 


\section{RESULTS}

\section{Amino acid analysis}

Amino acid analysis showed that RGD was successfully incorporated in the bulk of hydrogels via methacryloylglycylglycyl spacers. The amount of Arg and Asp in the hydrolyzate was used to calculate the amount of RGD incorporated into the hydrogels. Calibration curves (concentration versus area of the peak) obtained for arginine and tyrosine standards were used to calculate the amount of both amino acids in the hydrolyzate. The amount of peptides was $0.5 \mathrm{~mol} \%$ of MA-GlyGly-ArgGlyAsp (1.2\% RGD) and $0.36 \mathrm{~mol} \%$ (0.86\% RGD) for gel 1 and gel 2 respectively.

\section{ATR-FTIR spectroscopy}

Figure 2 shows the FTIR spectra of the polymer gel containing RGD (a) and an unmodified control polymer (b). Spectrum (a) is valid for gel 1 and gel 2 since both polymer gels show spectra with very similar characteristics. This Figure shows that gel a and gel $b$ exhibit very similar infrared features. However, the analysis of the infrared spectra of the individual components of the hydrogels (not shown) demonstrates that the $747 \mathrm{~cm}^{-1}$ feature is due to the HEMA spectral contribution. Thus, the RGD peptide in the hydrogel should be detected by subtracting the infrared spectra of the control polymer $b$ from that of the polymer a, using the $747 \mathrm{~cm}^{-1}$ peak as an internal intensity standard. As a result, the subtraction spectrum (c) clearly exhibits (despite a poor signal to noise ratio due to the very low concentration of the peptide) features characteristic of RGD such as the carbonyl $(\mathrm{C}=\mathrm{O})$ and $\mathrm{C}-\mathrm{O}$ stretching modes vibration of the acidic functions of Arg at 1721 and $1160 \mathrm{~cm}^{-1}$ respectively, and the amide I and amide II bands characteristic of the peptide bonds at 1676 and $1577 \mathrm{~cm}^{-1}$, respectively. It may be noted that both spectra show very similar characteristics. Even though these data do not demonstrate that the RGD is covalently bound to the polymer gel, it is clear that the peptide is successfully coupled to the HEMA-HPMA copolymer.

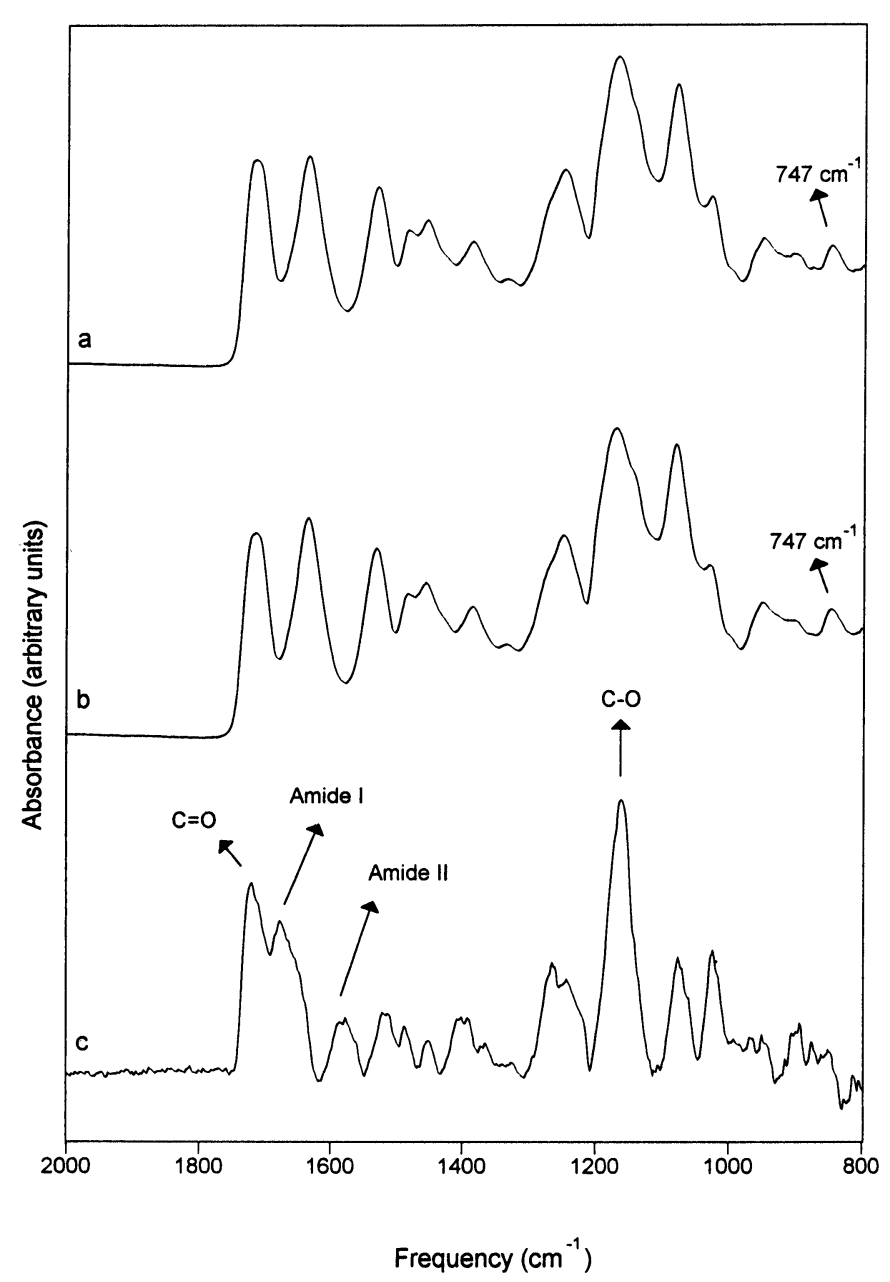

Fig. 2: ATR-FTIR spectra of: (a) polymer gel containing RGD peptide sequence; (b) unmodified polymer gel and (c) subtraction spectrum of (a) minus (b) (see result for details).

\section{Findings at autopsy}

All animals that received polymer gel implants survived to the schedule date of sacrifice. Neither neurological deficits nor abnormal behaviors were observed during the two-month survival period.

\section{Histology}

The hydrogels were readily recognized in the dorsal striatum on H\&E-stained brain sections observed at low magnification. The gel implants were encased in the host tissue without damage to the adjacent tissue (see Fig. 4B). In a few instances the polymer gel penetrated the corpus callosum and the 
adjacent layers of the cerebral cortex. In all cases the implants were surrounded by a mild-to-dense cellular reaction, mainly of glial origin as demonstrated by immunohistochemistry (vide infra). High magnification showed that cell spreading occurred in the marginal structures of the RGD-containing polymer gel (Fig. 3), but cell spreading could also have extended deeper in the gel along the surface of defects as seen by immunocytochemistry (see Fig. 5C). The unmodified polymer gels did not show tissue ingrowth and remained acellular.

Differences in tissue adhesiveness were found between polymer implants containing RGD and unmodified polymer. Polymer gel containing peptides showed stronger adhesion to the host tissue than the unmodified polymer as there was no or little partition between the gels and the host tissue. Control polymer gels had either lost contact at the polymer-tissue interface or showed a discontinuous interface. No evidence of polymer degradation or toxicity was found, and the architecture of the striatum in all cases appeared normal.

\section{Immunocytochemistry}

Immunocytochemical analysis of GFAP-stained tissue sections revealed that both control and modified gels were associated with low-grade gliosis in the surrounding host tissue when compared to control lesions. The gliosis had developed

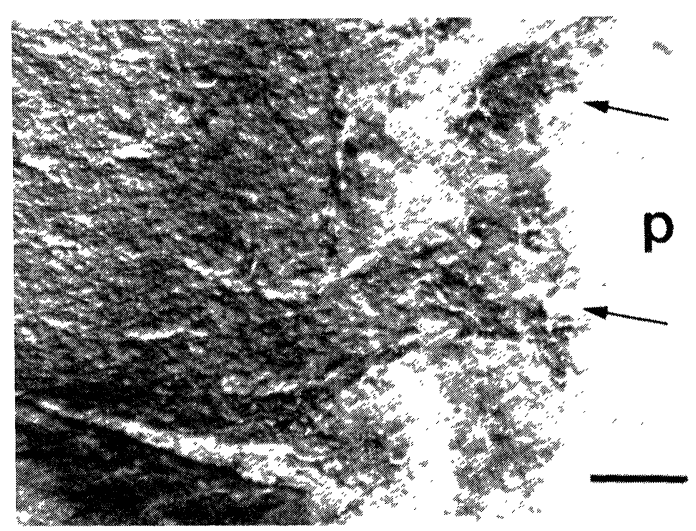

Fig. 3: Photomicrograph taken with Hoffman modulation optics (HMO) of an H\&E stained brain section after implantation of a RGD-grafted polymer gel (P) showing the infiltration of the polymer gel by host tissue cells (arrows). Bar: $100 \mu \mathrm{m}$ at and around the polymer-striatum interface and was characterized by tightly packed GFAP-positive astrocytes and processes. Control lesions and the wound created by the implantation needle were also associated with intensely GFAP-positive astrocytes (e.g., Fig. 4A). Furthermore, the intensity of GFAPimmunostaining decreased away from the implantation site. However, there were differences in the organization of the gliosis between the two types of gel implants. The unmodified polymer gels showed marked GFAP-immunostaining along the edge structure while the bulk of the gels did not show any visible staining (Figs. 4A-4B). In contrast, peptide-grafted polymer implants were positively immunostained for GFAP, but immunostaining was seen only in localized regions of a gel section and could not be seen through consecutive serial sections. Immunolabelled cellular patterns could be observed at the surface and within the gel by focusing throughout the $40 \mu \mathrm{m}$-thick gel slice. GFAP immunofluorescence was comparable in intensity of the reaction to that of the astrocytes of the scar in the surrounding tissue or to that which occurred in control lesions. Reactive astrocytes located immediately adjacent to the polymer implant extended intensely stained GFAP-positive processes along the surface and within the polymer implant (Fig. 5A), or formed a discrete tissue bridge in contact with the polymer gel from both sides of the host tissue (Fig. 5B). Although the extent of immunostaining was usually limited to the marginal layer of the gel, it reached the deeper layers of the implant in instances where processes migrated along the surface of gel defects or cracks (Figs. 5C-5D). Results were similar within this group of animals, and there were no significant differences between the gels containing different amounts of peptides.

Examination of brain sections immunostained with antibodies to neurofilaments revealed the absence of fluorescence signal at the surface and within the control gel implants; positively immunostained neurofilaments were seen only along the edge of the gel implant and in the host striatum, which showed a typical patchy organization. Gel implants containing RGD peptides were immunopositive after treatment with neurofilament antibodies. Intensely immunostained nerve fibers of striatal origin and, when the polymer gel contacted 

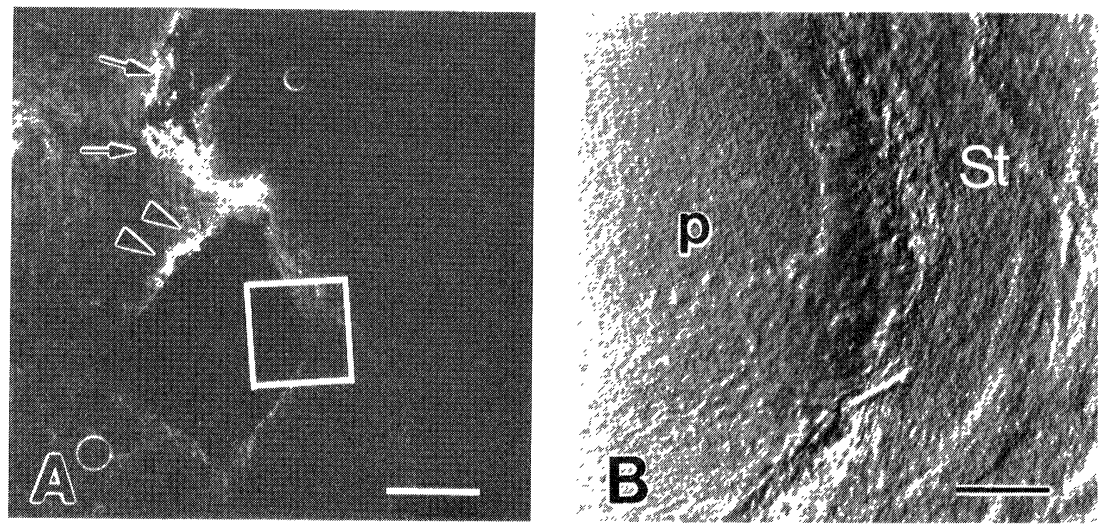

Fig. 4: Brain section containing an unmodified control polymer gel after immunostaining with GFAP antibodies (A) and under HMO (B). (A) Low-magnification photomicrograph showing a marked zone of GFAP-positive astrocytes along the transcortical implantation track (arrows) and at the dorsal aspect of the polymer implant (arrowheads), while the remainder of the gel implant is surrounded by a thin zone of reactive astrocytes. Note the absence of immunostaining of the gel. (B) High-magnification photomicrograph of the area indicated in (A), showing the close apposition between the polymer gel (P) and the host striatum (St). Bars: A, $500 \mu \mathrm{m} ; \mathrm{B}, 10 \mu \mathrm{m}$
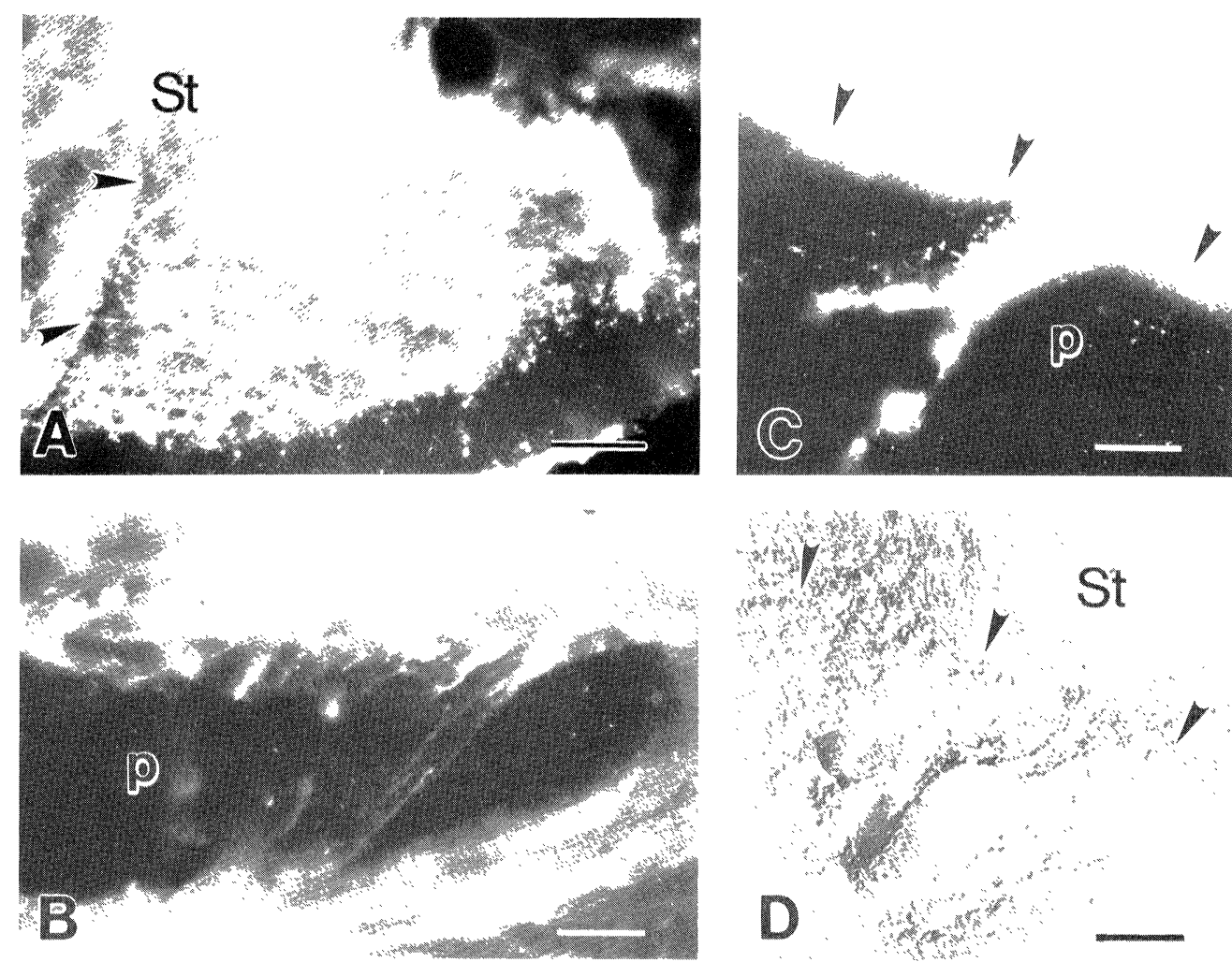

Fig. 5: Fluorescence photomicrographs of three different brain sections containing RGD-grafted polymer gels after staining with GFAP antibodies (A-C). (A) is the polymer implant/brain interface (arrowheads) showing spreading of reactive astrocytes and their processes from the striatum (St) onto the polymer surface. (B) GFAP-positive astrocytic fibers have grown in contact with the polymer surface $(\mathrm{P})$ to form a bridge between the two interfaces of the host. (C) GFAP-positive astrocytic fibers have spread along the surface of a crack in the polymer gel (P). (D) is identical to (C) under HMO showing the defect in the structure of the polymer gel. Bars: $25 \mu \mathrm{m}$ 
the adjacent cortex, of cortical origin were seen clearly growing onto and into the polymer gel sections. Figure 6 shows two examples of the host tissue reaction after neurofilament immunostaining. In one case, regeneration of long individual axons was seen on a tissue section that included the entire surface of the gel and showed the growth of nerve fibers originating from the adjacent host tissue onto the gel surface (Figs. 6A-6B). In other cases, the gels showed a punctuated fluorescence resembling densely associated axonal sprouts (Figs. 6C-6D). Nerve fibers could also be seen on the upper and lower surfaces of the gel section as they had penetrated the gel implant.

Laminin immunoreactivity was associated with proliferating blood vessels and was moderate in the vicinity of the implantation site while it was intense along the wound of the needle track (Figs. 7A-7B). For the same survival period, the control lesions that included the cortex down to the dorsal striatum were the site of dense scar tissue positively immunostained for GFAP without evidence of axonal regeneration through the wound.

\section{DISCUSSION}

The main findings of this study are: (i) that RGD peptides were successfully immobilized in HPMAbased polymer matrices via glycylglycine spacer arms. Amino acid analysis and ATR-FTIR confirmed that the coupling of the peptide was achieved; (ii) that RGD-grafted polymer substrates mediate a host tissue reaction involving glial proliferation and axonal regeneration.

The RGD peptide, a cell-adhesion sequence found in a large number of extracellular matrix proteins $/ 30 /$, is specifically recognized by integrin cell surface receptors $/ 5 /$. This recognition system is involved in cell-matrix and cell-cell attachments, spreading and growth $/ 20 /$, and has been demonstrated to be expressed by astrocytes $/ 26 /$ and by neuronal cells /19/. Therefore, in comparison with the unmodified gel implants, it is reasonable to think that the observed behavior of regenerating axons and astrocytes on RGD-grafted polymer was influenced by the immobilized peptides on the polymer surface. Interaction of reactive astrocytes with the modified polymer implants may involve focal contacts through the expression of integrin receptors, as has been shown in vitro /26/. Likewise, axonal regeneration on the surface of the substrate may occur through the expression of specific integrin receptors, which have been shown to be overexpressed following injury $/ 8$. Such interactions are highly specific; exogenous RGD peptide is able to inhibit neuronal attachment and growth when neuronal cells are plated onto RGDcontaining protein fragments /13/. Although surface adsorption of plasma proteins (e.g., fibronectin, albumin) onto the polymers may favor cell attachment and growth, it is unlikely that this occurred here, since the unmodified polymer gel did not support tissue growth and spreading.

The observation that spreading of glial cells and axonal growth occurred only in very localized regions of implants suggests that the chemical and physical characteristics of the polymer hydrogels may also be important in the interactions of the host cells with the polymer. For instance, the limited growth of cells and processes onto the polymer may result from the dependency that cells with RGDgrafted polymer have on some complex factors such as peptide surface density, expression of the RGD recognition integrin receptors, spatial conformation and accessibility of the peptide. Thus, we can speculate that the density of immobilized RGD peptides was non-uniform throughout the gel matrix, while interactions resulting in successful tissue proliferation would be dependent on a threshold value of RGD concentration, as has been shown with other cell-type cultures $/ 6,11 /$. Also, the structure of the gels may have influenced tissue growth; a micro- or non-porous surface induces the formation of a tissue scar that further impedes the growth of nerve fibers, while a porous structure facilitates tissue ingrowth and organization $/ 27 /$.

There are several lines of evidence that suggest that inhibition of axonal regeneration in the central nervous system may be the result of the effect of different factors: absence of appropriate substratebound neuroregenerative molecular cues $/ 9 /$, formation of a glial scar $/ 17 /$ and presence of growthinhibitory molecules from central myelin $/ 23 /$ or from extracellular matrix $/ 1,12 /$. Our results show the importance of growth-promoting molecular cues for sustained axonal regeneration and, at the same 

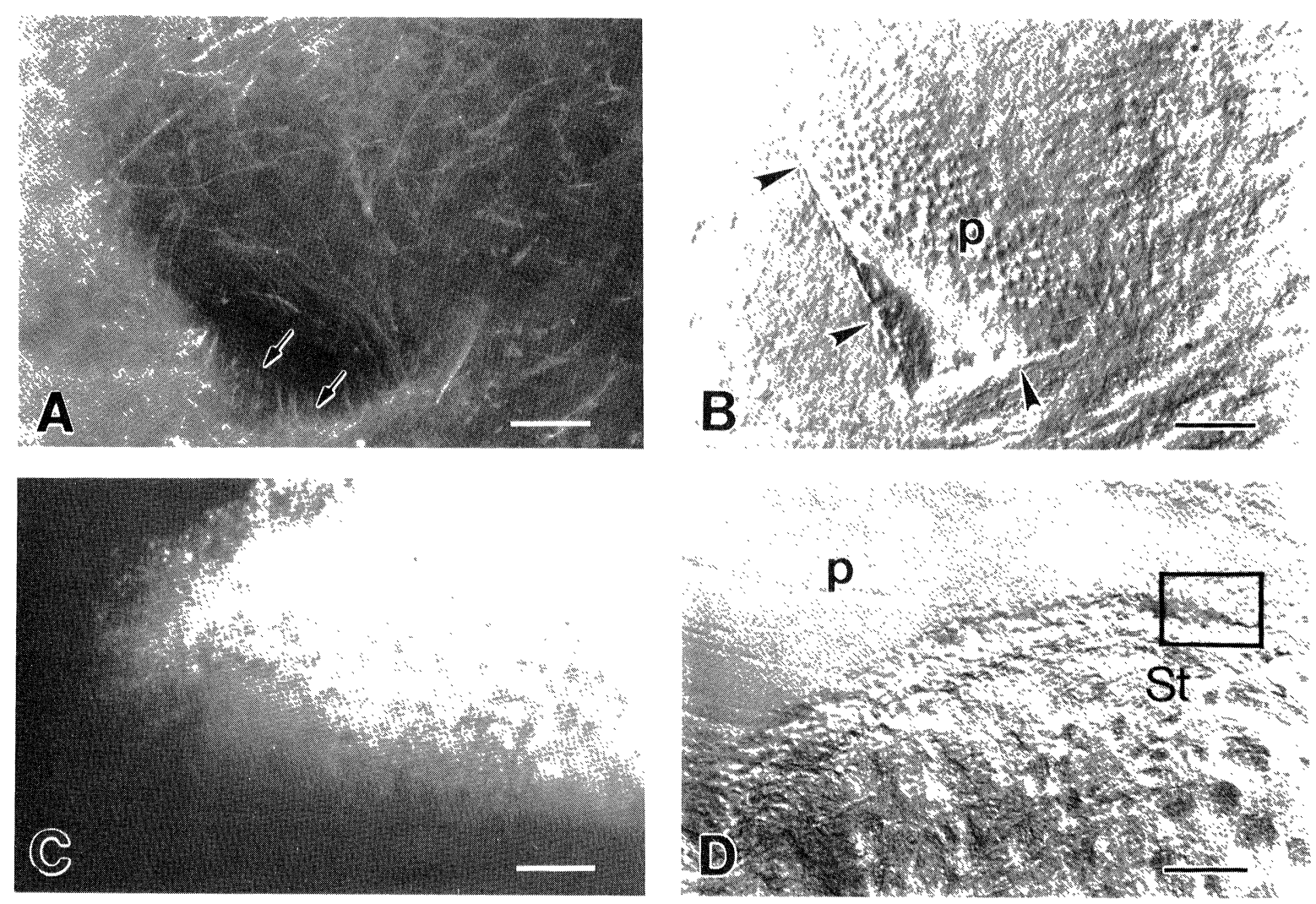

Fig. 6: Fluorescence photographs of brain sections including RGD-grafted polymer gels after immunostaining with antineurofilament antibodies. (A) Numerous regenerating axons of striatal origin are seen coursing onto the surface of the gel, covering almost the entire surface, while other axons seem to have penetrated the polymer matrix (arrows). (B) A view of the same section under HMO; the limit of the gel implant (arrowheads) can be seen to merge with the brain tissue. (C) High-magnification photomicrograph showing punctuated immunostaining of axons at the interface with the polymer gel. This view corresponds to the region depicted by the square in (D), at lower magnification under HMO which shows the polymer gel (P) in contact with the striatum (St). Bars: A and B, $50 \mu \mathrm{m} ; \mathrm{C}, 15 \mu \mathrm{m} ; \mathrm{D}, 75 \mu \mathrm{m}$
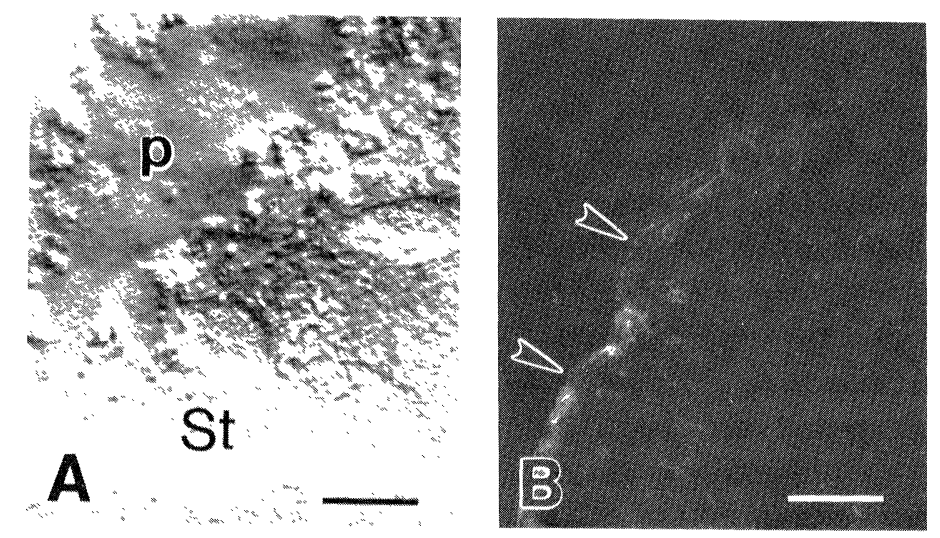

Fig. 7: (A) Brain tissue section through the striatum (St) under HMO showing structure details of the interface with the polymer implant (P). (B) Same view after laminin immunostaining showing numerous stained blood vessels and the immunopositive interface (arrowheads). Bars: $20 \mu \mathrm{m}$ 
time, suggest that if such cues are available at the site of injury, reactive gliosis which occurs at the interface might not impede axonal regeneration. This hypothesis is in agreement with the current controversy concerning the traditional view of the glial scar as a mechanical barrier to axonal growth and a more modern view of astrocyte's modulatory response to injury $/ 17 /$. On the other hand, it is known that reactive astrocytes do not support neuronal attachment or growth of neurites $/ 21 /$.

Therefore, regeneration in our model is due to positive interactions of growing nerve fibers with the RGD-bound substrate, and this suggests that immobilized RGD peptides provide a strong enough stimulatory effect to overcome the inhibitory influence of the astrocyte scar and related molecules. We propose that regeneration of central axons can be induced either by suppressing inhibitory factors to regeneration as previously demonstrated $/ 22 /$ or, as demonstrated here, by providing a substrate with neuroregeneration molecular cues.

This study has shown that it is feasible to modify brain healing, particularly the astrocytic reaction, and to promote axonal regeneration by means of polymer matrices into which bioactive peptides have been integrated. Although this study has shown that substrate-bound RGD favors axonal regeneration, other peptides (natural or synthetic) have been identified as interacting specifically with neuronal cells to promote regeneration. Thus, laminin pentapeptides of various sizes have been shown to support cell attachment and axonal growth $/ 7,10,15$, 25/. Taken together, these results allow us to envisage the possibility of engineering healing in the CNS in a direction that would lead to tissue restructuring at the wound site and axonal regeneration. This could be achieved by providing a wellcontrolled molecular environment that mediates the cellular and molecular mechanisms that are required for tissue regeneration and organization /28/. However, if we consider the diversity of receptors involved in cellular interactions with substrate-bound molecules and the various modes of these molecular interactions that occur during regeneration and development, engineering brain wound healing and regeneration will probably imply the binding of several peptides of various sequences and sizes to elicit specific cell interactions $/ 2 /$.

\section{ACKNOWLEDGEMENTS}

This work was supported by the Medical Research Council of Canada and the Fond de la Recherce en Santé du Québec.

\section{REFERENCES}

1. Bovolenta P, Wandosell F, Nieto-Sampedro M. Neurite outgrowth inhibitors associated with glial cell lines. Neuro Report 1993; 5: 345-348.

2. Douville $\mathrm{P}$, Carbonetto $\mathrm{S}$. Extracellular matrix adhesive glycoproteins and their receptors in the nervous system. In: Margolis RU, Margolis RK, eds. In: Neurobiology of Glycoconjugates. New YorkLondon: Plenum Press, 1989; pp. 383-409.

3. Harper SJ, Walsh FS, Doherty P. Neurite outgrowth of spinal neurons on tissue sections of embryonic muscle is largely integrin dependent. Neurosci Lett 1993; 159 : 202-206.

4. Hirano Y, Okuno M, Hayashi T, Goto K, Nakajima A. Cell-attachment activities of surface immobilized RGD, RGDS, RGDV, RGDT and YIGSR toward five cell lines. J Biomater Sci Polymer 1993; 4: 235-243.

5. Hynes RO. Integrins: versatility, modulation, and signaling in cell adhesion. Cell 1992; 69: 11-25.

6. Ito $\mathrm{Y}$, Kajihara $M$, Imanishi $Y$. Materials for enhancing cell adhesion by immobilization of celladhesive peptide. J Biomed Mat Res 1991; 25: 13251337.

7. Jucker M, Kleinman HK, Ingram DK. Fetal rat septal cells adhere to and extend processes on basement membrane, laminin, and a synthetic peptide from the laminin A chain sequence. J Neurosci Res 1991; 28 : 507-517.

8. Lefcort F, Venstrom K, McDonald JA, Reichardt LF. Regulation of expression of fibronection and its receptor, $\alpha 5 \beta 1$, during development and regeneration of peripheral nerve. Development 1992; 116: 767-782.

9. Liesi P, Silver J. Is astrocyte laminin involved in axon guidance in the mammalian CNS? Dev Biol 1988; 130: 774-785.

10. Liesi P, Narvanen A, Soos J, Sariola H, Snounou G. Identification of a neurite outgrowth-promoting domain of laminin using synthetic peptides. FEBS Lett 1989; 244: 141-148

11. Lin H-B, Sun W, Mosher DF, Garcia-Echeverria C, Shaufelberger K, Lelkes PI, Cooper SL. Synthesis, surface and cell-adhesion properties of polyurethanes containing covalently grafted RGD-peptides. J Biomed Mat Res 1994; 28 : 329-342.

12. McKeon RJ, Schreiber RC, Rudge JS, Silver J. Reduction of neurite outgrowth in a model of glial scarring following CNS injury is correlated with the 
expression of inhibitory molecules on reactive astrocytes. J Neurosci 1991; 11: 3398-3411.

13. Neugebauer KM, Reichardt LF. Cell-surface regulation of $\beta_{1}$-integrin activity on developing retinal neurons. Nature 1991; 350: 68-71.

14. Prieto AL, Edelman GM, Crossin KL. Multiple integrins mediate cell attachment to cytotactin/ tenascin. Proc Natl Acad Sci USA 1993; 90: 1015410158

15. Ranieri JP, Bellamkonda R, Aebischer P. Molecular control of neural cell attachment and differentiation on polymer surfaces engineered with laminin oligopeptide sequences. Proc Soc Biomaterials 1994; p. 353.

16. Reichardt LF, Tomaselli KJ. Extracellular matrix molecules and their receptors: functions in neural development. Ann Rev Neurosci 1991; 14: 531-570.

17. Reier PJ, Lawrence F, Jakeman L. Reactive astrocyte and axonal outgrowth in the injured CNS: is gliosis really an impediment to regeneration? In: Neural Regeneration and Transplantation. New York: Alan R. Liss Inc., 1989; pp. 183-209.

18. Rejmanova P, Labsky, Kopeck J. Aminolysis of monomeric and polymeric p-nitrophenyl esters of methacryloyated amino acids. Makromol Chem 1977; 178: 2159-2168.

19. Rogers SL, McCarthy JB, Palm SL, Furcht LT, Letourneau PC. Neuron-specific interactions with two neurite promoting fragments of fibronectin. J Neurosci 1985; 5: 369-378.

20. Ruoslahti E, Pierschbacher D. New perspectives in cell adhesion: RGD and integrins. Science 1987; 238: 491497.

21. Rudge JS, Silver J. Inhibition of neurite outgrowth on astroglial scars. J Neurosci 1990; 10: 3594-3603.

22. Schnell L, Schwab ME. Rat cortical tract fibers regenerate in the presence of antibodies to myelinassociated neurite growth inhibitors. Rest Neurol Neurosci 1991; 2: 248-250.

23. Schwab ME, Caroni P. Rat CNS myelin and a subtype of oligodendrocytes in culture represent a nonpermissive substrate for neurite growth and fibroblast spreading. J Neurosci 1988; 8: 2381-2393.

24. Strohalm J, Kopecek J. Poly [N-(2-hydroxypropyl) methacrylamide]. Heterogeneous polymerization. Angew Makromol Chem 1978; 70: 109-118.

25. Tashiro K, Sephel GC, Weeks B, Sasaki M, Martin GR, Kleinman HK, Yamada YA. Synthetic peptide containing the IKVAV sequence from the A chain of laminin mediates cell attachment, migration and neurite outgrowth. J Biol Chem 1989; 27: 1617416182.

26. Tawil N, Wilson $\mathrm{P}$, Carbonetto $\mathrm{S}$. Integrins in point contacts mediate cell spreading: factors that regulate integrin accumulation in point contact vs focal contacts. J Cell Biol 1993; 120: 261-271.

27. Woerly S, Marchand R, Lavallée C. Intracerebral implantation of synthetic polymer/biopolymer matrix: a new perspective for brain repair. Biomaterials 1990; 11: 97-107.

28. Woerly S, Maghami G, Duncan R, Subr V, Ulbrich K. Synthetic polymer derivatives as substrata for neuronal adhesion and growth. Brain Res Bull 1993; 30: 423432.

29. Woerly S, Plant G, Harvey A. Neuronal and glial cells entrapped within poly[N-(2-hydroxypropyl) methacrylamide] polymer matrices: a potential tool for transplantation. Rest Neurol Neurosci (submitted) 1994.

30. Yamada KM. Adhesive recognition sequences. J Biol Chem 1991; 266: 12809-12812. 

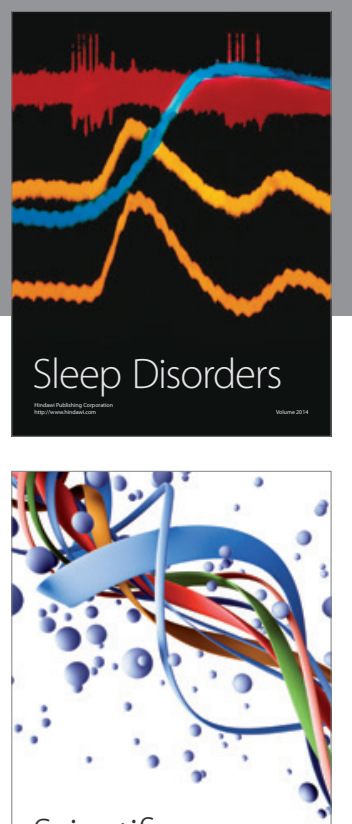

Scientifica
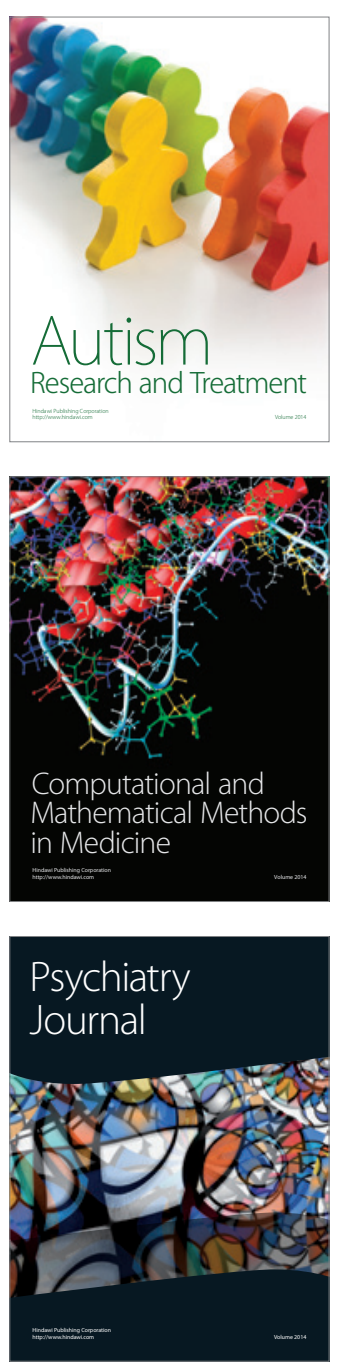
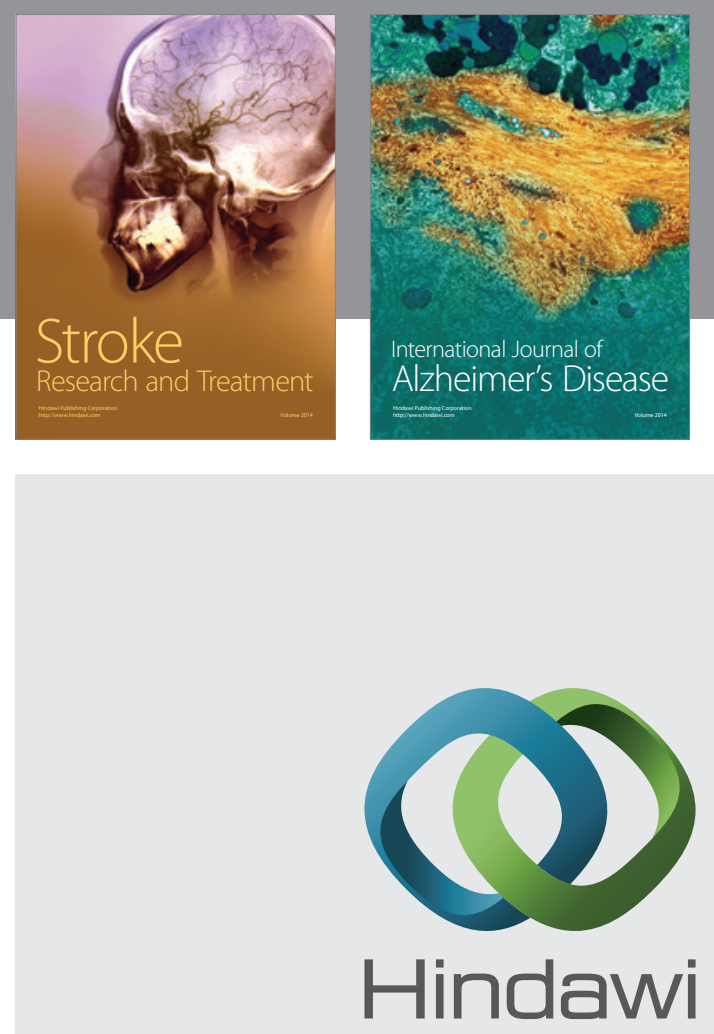

Submit your manuscripts at

http://www.hindawi.com
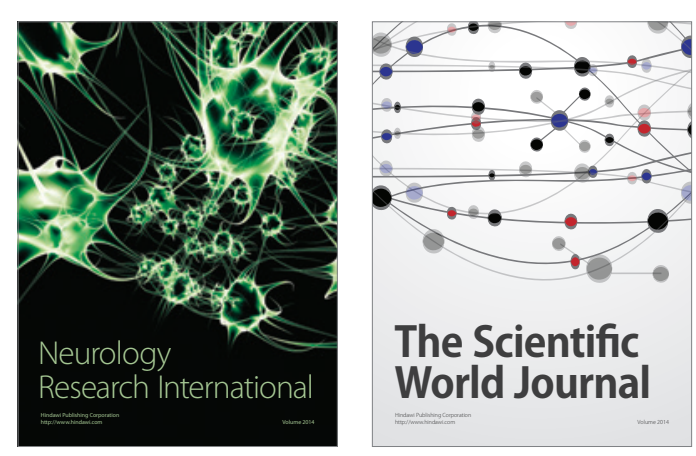

The Scientific World Journal

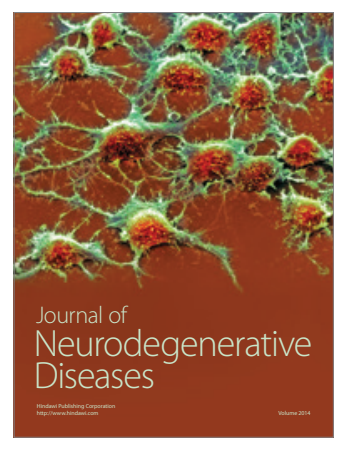

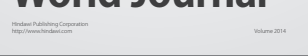

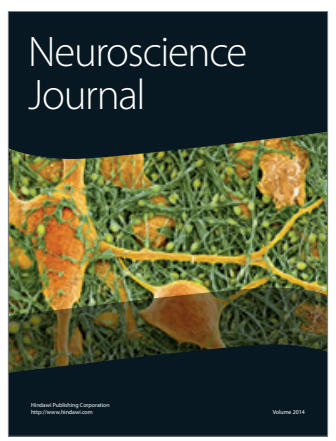

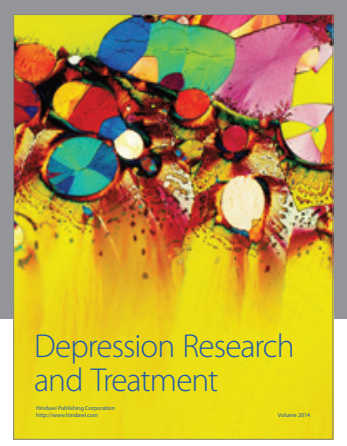
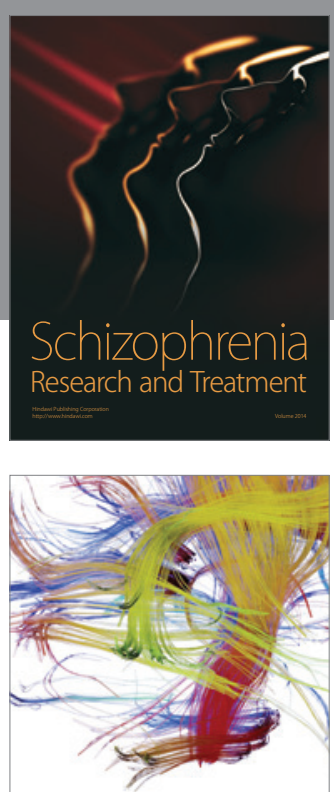

Brain Science

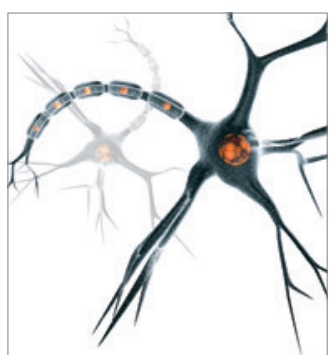

Neural Plasticity
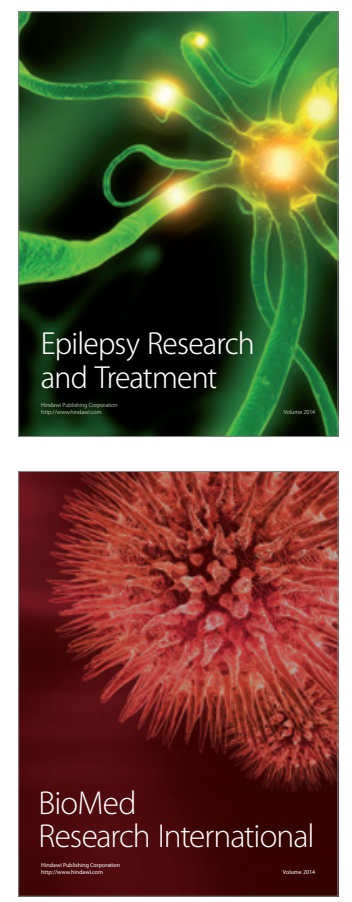

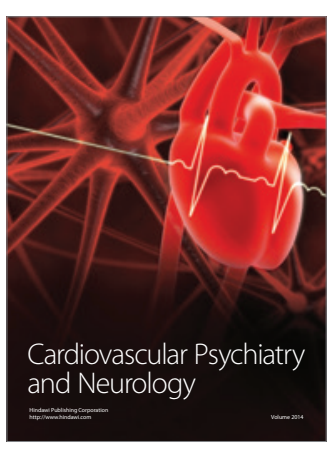

Parkinson's

Disease
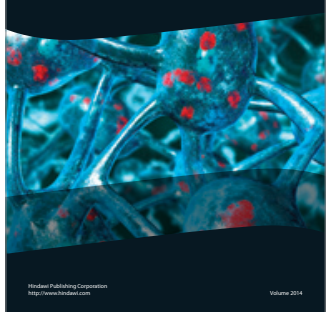